\title{
Exploring the Determinants of Fuel wood Use in Western Hill Nepal: An Econometric Analysis
}

\author{
Lekha Nath Bhattarai, Ph. D*
}

\begin{abstract}
Forest resources use at the household level may be determined by socio-economic as well as physical factors adjacent to the users. This paper is based on the study conducted by the author to explore the determinants of fuelwood use at household level with field survey data from the samples of households along the stretch of middle hills in Arghakhanchi District, west Nepal. The findings of multiple regression analysis clearly suggest that the physical quantity of fuelwood used per capita is significantly influenced by the households' socio-economic indicators such as income, household size, landholding, and domestic animal holding and to some extent caste and ethnicity. Similarly, the distance to nearest forest is also an important predictor, exhibiting negative and significant effect. But the net effects of per capita landholding on per capita fuel wood collected from public forest appeared to be negative. It is not only an indication of higher dependency of poor on public forests but also an evidence of manifestation of their deprivation. It leads to imply a fact that the use of forest resource such as fuelwood can be reduced increasing the socio-economic status of the users.
\end{abstract}

Keywords : Fuel wood, determinants of use, public/private forest, socio-economic variables, regression models.

\section{INTRODUCTION}

Nepal has been experiencing significant deforestation since long. For rural area forest depletion is one of the most felt environmental challenges. Forest resource is under great pressure for meeting firewood, fodder, timber and other purposes. The increasing demand and extensive use of forest products and lands owing to increasing human and livestock population have created substantial pressure on forest and led to its lessening both in area and quality (UNEP, 2001). There is a general belief that the forest degradation in rural Nepal has become both a contributing cause of poverty as well as its consequences. It is believed to be more pronouncing in the rural hills. Owing to the increasing pressure of population, both these problems are reinforcing each other in the context of subsistence agriculture (Thapa and Weber 1988).

Forest resources use at the household level may be determined by socio-economic as well as physical factors such as income, land holding, livestock holding, caste and ethnicity of the households, and access to resources and the state of technology in and around the users. Similarly, there might be differential effects of variables on the resources use pertaining to different sources such as collected from public forest or privately owned forest and pasture land. Forest resource use is not an independent activity;

\footnotetext{
* Dr. Bhattarai is Associate Professor of Economics, Prithvi Narayan Campus, T.U., Pokhara.
} 
rather it may depend on or influenced by socio-economic variables at the household level. It means forest resources use is a function of households' economic activities as well as household status. Similarly, variables related to physical environment such as distance to the nearest forest, area under forest and its density and other geographical features might be some other determinants. The earlier evidences clearly suggest that heterogeneity in socio-economic status of the household has vital role in determining the level and variation of forest resource use at household level (Bajracharya, 1986; Shrestha, 1986; Amachar et.al, 1996, 1999; UNEP, 2001; Adhikari, 2003; Bhattarai, 2004). So, it is in this background this paper attempts to explore the socioeconomic and physical determinants of fuelwood use at the household level applying econometric techniques.

\section{DATA AND METHODS}

The main body of research is exclusively based on cross-section data collected by the author from Western Hills Nepal. The western hills region of Nepal covers Tanahu, Palpa and Arghakhanchi districts. Out of these three districts, Arghakhanchi was purposively selected for this study. For the survey only the Mahabharat tract of the district was considered as study area. Both purposive and simple random sampling techniques were applied to determine the sample and sub-samples. Two stage sampling procedure were followed. In the first stage, two wards each were purposively selected from each VDC, out of nine wards, considering the fact that the selected wards would properly represent both the regions and the socio-economic diversities of the households. Ultimate stage of sampling was to select the households to be surveyed. Household units to be surveyed were determined at 15 percent of the total households in the respective wards based on the record of VDCs and information obtained from ward chairperson. Therefore, the total sample size turned out to be 269 households. For the selection of the households simple random sampling technique was followed, i.e. the required numbers of household were chosen randomly without replacement applying lottery method on the basis of the then (i.e. March 2002) latest voter's list of the respective wards. At last, total 265 could be surveyed.

The main body of this research is based on data and information collected at the household level conducting a sample survey of the randomly selected households in the selected VDCs and wards of the study area. A structured interview schedule was prepared and administered to this purpose. The schedule was pre-tested before finalizing it. Then, heads of the household were interviewed to fill up the structured interview schedule.

\section{Multiple regression analysis}

Multiple regression analysis has been applied to explore the impact of various socio-economic and other indicators on different attributes of forest resources use. Two kinds of regression models have been applied for this purpose.

\section{A. Linear regression models \\ Model specification}

To investigate socio-economic and other determinants of forest resources use at the household level, the linear and log linear regression models are applied. The specification of the OLS type linear model is as follows:

$$
Y_{i}=\alpha+\beta_{1} X_{1 i}+\beta_{2} X_{2 i}+\ldots .+\beta_{K} X_{k i}+\varepsilon_{i}
$$

After natural $\log$ transformation of the dependent variable the model specification would be as:

$$
\ln \left(Y_{i}\right)=\alpha+\beta_{1} X_{1 i}+\beta_{2} X_{2 i}+\ldots \ldots+\beta_{k} X_{k i}+\varepsilon_{i}
$$




\section{8 / Lekha Nath Bhattarai}

Where, $\mathrm{Y}_{\mathrm{i}}$ denotes the per capita physical quantities of different forest resource used per year by ${ }_{\mathrm{i}}$ th household. (Note: There are five uses of forest resources under consideration, namely fuel wood, fodder/litter, grazing, timber and other minor forest product. Thus, these variables were used as $Y_{i}$ in the regression models separately. Additionally, two variables such as per capita fuel wood and per capita fodder/litter collected from public forest were also used as $Y_{i}$ in separate regression model. Finally, composite index of overall forest resource use used as dependent variable $\left(\mathrm{Y}_{\mathrm{i}}\right)$. So, altogether eight regression equations were explored in total with different sets of explanatory variables.). $\ln \left(\mathrm{Y}_{\mathrm{i}}\right)$ denotes the natural log transformation of the dependent variables stated above.

$\mathrm{X}_{1 \mathrm{i}}, \mathrm{X}_{2 \mathrm{i}}, \ldots \ldots . ., \mathrm{X}_{\mathrm{ki}}$ are predictor ( explanatory) variables including dummy variables (i.e. there are different sets of explanatory variables in different regression equations, which are given in box 1 below). $\alpha, \beta s$ are parameters to be estimated and $\varepsilon_{\mathrm{i}}$ the error term.

Stepwise (forward) model selection method was applied to select the sets of explanatory variables and to choose the best-fit model. The minimum value of $\mathrm{F}$ to enter the additional predictors to the model was specified at alpha level 0.2. Similarly, while selecting the variable in the model the value of $R^{2}$ and adjusted $\mathrm{R}^{2}$ also were taken into consideration, i.e. whether the new variable entered into the model was contributing to enhance the values of $\mathrm{R}^{2}$ and adjusted $\mathrm{R}^{2}$ or not. Similarly, some explanatory variables which were showing high collinearity were also dropped on the basis of estimated VIF (or alternatively tolerance level i.e.1/VIF). Finally, the sets of explanatory variables selected for the regression equations are given in Box 1:

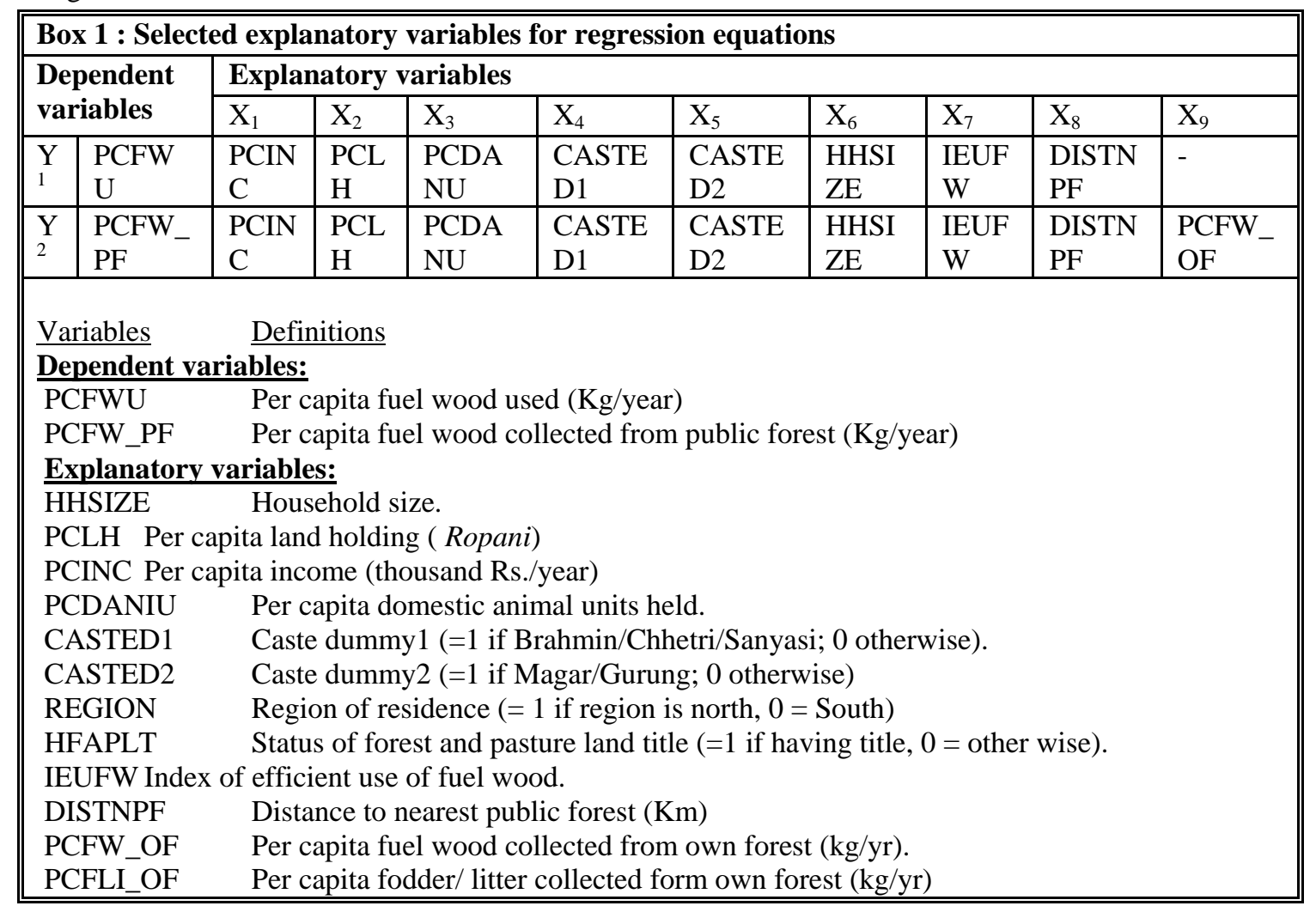


Exploring the Determinants of Fuel wood Use ...../29

\section{Diagnostic tests}

After model selection, probable outlier and regression diagnostics such as non linearity and heteroscedasticity were checked examining different residuals plots of the estimated regression equations (i.e. rvfplot, lvr2plots, avplots, normal probability plot, Kernel density plot and box plots of studentized residuals) with the help of statistical software package-STATA version 7.0 ( Stata Corporation, 2001). Those extreme outliers (observations) which were identified as to have serious influence on the parameter estimates were dropped. Since this study is based on the cross section field survey data, the heteroscedasticity problem is obvious. Cook-Weisberg test for heteroscedasticity (i.e the 'hettest' command in STATA) was also applied to find out the seriousness of the problem. The correction of the problem could be succeeded by transforming the dependent variable into natural logarithm.

\section{B. Tobit (censored regression) model}

Econometricians have suggested an alternative model, censored regression model (also called Tobit model), for better estimation of the parameter in case if dependent variable comprises numbers of zero observations (cited in Gujarati 2003: 616-20). In the present study also for some dependent variables such as per capita fuel wood collected from public forest, per capita fodder/litter collected from public forest and per capita grazing animal held, numbers of observations contain zero value, as respondents reported that they were not using or not having. In such case or simply dropping the cases would reduce the degree of freedom affecting adversely the overall significance of the model and the significance of the estimated parameters and the OLS estimates would be biased in such cases. So, it would be appropriate to run the Tobit model, which follows the maximum likelihood methods of estimation. Hence, the typical specification of the Tobit model would be as follows:

$$
Y_{i}=\alpha+\beta_{1} X_{1 i}+\beta_{2} X_{2 i}+\ldots \ldots . .+\beta_{k} X_{k i}+\varepsilon_{i} ; \text { If RHS }>0 \text { and }=0 \text { otherwise } \ldots . . .(1 \mathrm{c})
$$

Where, the definition of the terms included in the model are as same as in equation (1a) besides the fact that $\mathrm{Y}_{\mathrm{i}}$ having zero observation is censored and rest of the observations are used in the model as uncensored. It is to be noted here that the interpretation of the estimated parameters would be same as in model (1a). Only difference is that instead of $R^{2}$ and $F$ statistics, the model gives pseudo $R^{2}$ and LR Chisquare, for testing significance of the model.

\section{RESULTS AND DISCUSSION}

\section{Extent of fuel wood use}

The overall picture of per capita use of different attributes of traditional fuel in the study area by VDCs is presented in Table 4.2. The table reveals that the average magnitude of traditional fuel used per capita is estimated to be $656.24 \mathrm{~kg} /$ year in the study area, comprising $506.48 \mathrm{~kg}(77.0 \%)$ of fuel wood and 151.46 $\mathrm{kg}(23.0 \%)$ of crop residues. Out of total fuel wood used about two third is reported to be collected from public forest and remaining one third from private forest and pastureland. It means the dependency on public forest for fuel wood is 53.2 percent on average. However, the fuel wood use pattern varies across VDCs. For example, annual per capita magnitude of total traditional fuel use is found to have ranged from lowest $560.08 \mathrm{~kg}$ in Pokharathok to highest $735.42 \mathrm{~kg}$ in Jukena. In the case of fuel wood use too, the same VDCs have also recorded the lowest $(415.68 \mathrm{~kg})$ and highest $(563.68 \mathrm{~kg})$ magnitude. 
Table 1: Average quantities of traditional fuel used per capita in the study area by sources and VDCs ( in $\mathrm{kg} /$ year)

\begin{tabular}{||l|l|l|l|l|l|l||}
\hline VDCs & $\begin{array}{c}\text { Fuel wood } \\
\text { collected } \\
\text { from } \\
\text { public } \\
\text { forest }\end{array}$ & $\begin{array}{c}\text { Fuel wood } \\
\text { collected } \\
\text { from private } \\
\text { forest/pasture }\end{array}$ & $\begin{array}{c}\text { Fuel } \\
\text { wood } \\
\text { used }\end{array}$ & $\begin{array}{c}\text { Crop } \\
\text { residue } \\
\text { used as } \\
\text { fuel }\end{array}$ & $\begin{array}{c}\text { Total } \\
\text { Traditio } \\
\text { nal fuel } \\
\text { used }\end{array}$ & $\begin{array}{c}\text { Ratio of fuel wood } \\
\text { from public forest to } \\
\text { total traditional fuel }\end{array}$ \\
\hline 1 & 2 & 3 & $4=2+3$ & 5 & $6=4+5$ & $7=2 / 6$ \\
\hline Dhanachaur & 350.36 & 191.55 & 520.56 & 156.22 & 667.31 & 0.554 \\
\hline Dhatibang & 331.11 & 180.32 & 479.84 & 146.49 & 626.33 & 0.560 \\
\hline Dhikura & 364.41 & 222.81 & 548.20 & 160.80 & 709.00 & 0.548 \\
\hline Jukena & 211.53 & 380.31 & 563.68 & 171.75 & 735.42 & 0.309 \\
\hline Khanchikot & 314.60 & 179.35 & 476.67 & 135.68 & 606.70 & 0.537 \\
\hline Maidan & 325.87 & 239.54 & 513.48 & 136.47 & 649.95 & 0.527 \\
\hline Patauti & 324.77 & 230.97 & 532.10 & 174.93 & 707.02 & 0.466 \\
\hline Pokharathok & 310.39 & 129.21 & 415.68 & 144.40 & 560.08 & 0.555 \\
\hline Sitapur & 324.40 & 208.62 & 495.05 & 144.80 & 639.84 & 0.529 \\
\hline Subarnakhal & 415.94 & 117.14 & 501.13 & 138.97 & 640.10 & 0.670 \\
\hline All sample & $\mathbf{3 2 6 . 6 6}$ & $\mathbf{2 1 3 . 9 7}$ & $\mathbf{5 0 6 . 4 8}$ & $\mathbf{1 5 1 . 4 6}$ & $\mathbf{6 5 6 . 2 4}$ & $\mathbf{0 . 5 2 3}$ \\
\hline
\end{tabular}

Data source: field survey.

If we look at the sources of fuel wood, about two third of the fuel wood is obtained from public forest and remaining one-third from private forest and pastures on average. However, it varies across the sample VDCs. For instance, the highest dependency on public forest for fuel wood is found in Subarnakhal (83\%) followed by Pokharathok (75\%) and lowest in Jukena (38\%). Similarly, the annual average per capita use of crop/ fodder residue as fuel is highest in Jukena $(171.75 \mathrm{~kg}$ ) and lowest in Khanchikot (135.68 kg), however the difference here is quite low. Thus, it is clear that the observed differences seem to be associated with the differences in availability of fuel wood in their respective public forests and private land.

\section{Variation in fuel wood use between regions}

It is generally believed that the locations factor such as region is one of the significant factors leading to variation in resource use and dependency. So, it would be of interest to see whether this hypothesis would establish from the evidence of present study since there are two distinct regions along the Mahabharat tract in terms of geographical and socio-economic setting. Table 1 presents the average magnitude of use of the traditional fuel per capita by sources and regions along with ANOVA results.

Table 2: Per capita use of traditional fuel from different sources by region (in $\mathrm{Kg} / \mathrm{year}$ )

\begin{tabular}{||l|l|l|l|l|l|l||}
\hline \hline Regions & $\begin{array}{l}\text { Fuel wood } \\
\text { collected } \\
\text { from public } \\
\text { forest }\end{array}$ & $\begin{array}{l}\text { Fuel wood } \\
\text { collected } \\
\text { from private } \\
\text { forest/pastur } \\
\text { es }\end{array}$ & $\begin{array}{l}\text { Fuel } \\
\text { wood } \\
\text { used }\end{array}$ & $\begin{array}{l}\text { Crop } \\
\text { residue } \\
\text { used as } \\
\text { fuel }\end{array}$ & $\begin{array}{l}\text { Total } \\
\text { traditiona fuel } \\
\text { used }\end{array}$ & $\begin{array}{l}\text { Ratio of FW from } \\
\text { public forest to } \\
\text { total traditional } \\
\text { fuel used }\end{array}$ \\
\hline North & 315.95 & 206.26 & 496.00 & 153.97 & 647.56 & 0.512 \\
\hline South & 336.45 & 221.41 & 516.06 & 149.18 & 664.18 & 0.532 \\
\hline All sample & $\mathbf{3 2 6 . 6 6}$ & $\mathbf{2 1 3 . 9 7}$ & $\mathbf{5 0 6 . 4 8}$ & $\mathbf{1 5 1 . 4 6}$ & $\mathbf{6 5 6 . 2 4}$ & $\mathbf{0 . 5 2 3}$ \\
\hline ANOVA: & \multicolumn{7}{|l|}{} \\
\hline F & 1.380 & 0.681 & 1.422 & 0.273 & 0.48 & 0.515 \\
\hline Sig. & 0.241 & 0.41 & 0.234 & 0.602 & 0.489 & 0.474 \\
\hline
\end{tabular}

Data source: field survey. 
Exploring the Determinants of Fuel wood Use ...../31

Table 2 shows that per capita use of all the traditional fuels are found to be higher in the south region, except for the crop residue, which is slightly higher in the north. The dependence on public forest for fuel also found to be higher in the south. The observed difference in fuel wood use and dependency on public forest for the same between regions, however, is very low, i.e. only 5 percent and 2 percent respectively. The ANOVA results confirm it revealing that all the F statistics support the null hypothesis that there is no significant difference in forest resource use as fuel energy and the dependency. It clearly indicates the fact that the region is not a significant factor leading to variation in traditional fuel use including fuel wood.

\section{Exploring the factors determining fuel wood use: Econometric analysis}

Following the model specifications stated above in equations (1a), (1b) and (1c), regression models (linear, log-linear and Tobit) containing different sets of predictors were examined and tested for fuelwood use with the help of computer statistical package "STATA". The results of all the models have been presented and interpreted in the following sub-sections.

\section{Determinants of fuel wood use}

Table 3 reveals that eight variables were selected as predictors in the model including socio-economic indicators such as household income, landholding, domestic animal holding; and other indicators such as household size, distance to nearest public forest, and index of efficient use of fuel wood. Both the linear and log linear models are found to be highly significant as indicated by F statistics and P-value. The estimated $\mathrm{R}^{2}$ values reveal that these eight predictors have explained 54 and 57 percentage of the variation in the linear and log linear models respectively. Although the log-lin model seems to be better fitted than linear model it reveals presence of some degree of heteroscedasticity. However, there is no substantial difference in the sign, $t$ statistics and the significance level between the models. Thus further discussion is based on the results of linear model.

Table 3: Regression results for determinants of PCFWU

\begin{tabular}{|lcc|}
\hline Predictors & \multicolumn{2}{c|}{ Dependent Variable: PCFWU } \\
\hline & Linear model & Log-Lin model \\
\hline Constant & $624.873(18.09)^{* *}$ & $6.413(95.10)^{* *}$ \\
& & \\
PCINC (in thousands Rs) & $6.201(4.34)^{* *}$ & $0.011(4.11)^{* *}$ \\
PCLH (in Ropani) & $5.272(2.04)^{*}$ & $0.010(2.01)^{*}$ \\
PCDANIU & $14.886(1.52)$ & $0.021(1.11)$ \\
CASTED1 (B/C/S=1) & $61.436(3.65)^{* *}$ & $0.164(4.98)^{* *}$ \\
CASTED2 (M/G=1) & $84.909(4.79)^{* *}$ & $0.207(5.98)^{* *}$ \\
HHSIZE & $-25.194(10.35)^{* *}$ & $-0.052(10.86)^{* *}$ \\
IEUFW & $-27.719(0.63)$ & $-0.060(0.69)$ \\
DISTNPF & $-36.188(3.33)^{* *}$ & $-0.067(3.18)^{* *}$ \\
Summary statistics: & & \\
Observations & 265 & 265 \\
R ${ }^{2}$ Adj. R ${ }^{2}$ & $0.54 / 0.53$ & $0.57 / 0.55$ \\
F statistics (P-value) & $37.99(0.000)$ & $41.81(0.000)$ \\
Mean VIF & 1.54 & 1.54 \\
Cook-Weisberg test for & heteroscedasticity using & fitted value of dependent variable: Ho=constant \\
variance. & & \\
Chi2/p-value & $0.48 / 0.485$ & $11.70 / 0.001$ \\
\hline
\end{tabular}

Notes: 1. Absolute value of $\mathrm{t}$ statistics in parentheses

2. * significant at $5 \%$;** significant at $1 \%$ 
Among the eight predictors included in the models six came out to be statistically significant leaving two variables insignificant. The results come with expected sign of the coefficients, i.e. the predictors PCLH, PCINC, PCDANU and two caste dummies have exhibited positive effects on response variable, whereas HHSIZE, IEUFW and DISTNPF have shown negative effects for the same. This means every unit change in households' per capita income (thousand rupees) and per capita land holding (Ropani) independently lead to increase in per capita fuel wood use in the households by $6.20(1.10 \%)$ and $5.27 \mathrm{~kg}$ $(1.0 \%)$ per annum respectively, on the average, holding the effect of other variable in model constant. Similarly, the coefficients of the caste dummies reveals significant difference i.e. the first caste groups (Brahmin/Chhetri/Sanyasi) and second caste group (Magar/Gurung) use fuel wood per capita higher than the base category (i.e Dalits) by $61.44 \mathrm{~kg}(17.8 \%)$ and $84.91(23 \%)$ per annum, on the average, holding the effect of other variable constant.

The coefficient on HHSIZE reveals the negative effect of household size on fuel wood use per capita. It means unit increase in existing household size would reduce the per capita fuel wood use by $25.19 \mathrm{~kg}$ (5.3\%) per annum, holding other variable constant. This, however, does not necessarily mean that total amount of fuel wood use by the household's decreases in absolute term. It rather indicates that the economy of scale operates in this case. Even though the coefficient of IEUFW turned out to be negative and insignificant it indicates the expected direction of the effect because one can expect that if fuel wood is efficiently used it will certainly reduce the fuel wood consumption per capita; but the insignificant coefficient also indicate that the use of fuel wood saving technologies has been at the sub optimal level. Lastly, the coefficient of DISTNPF shows the negative and significant influence of accessibility factor (distance) on fuel wood use per capita. This means higher the distance to nearest public forest lower the use of fuel wood per capita, i.e. a kilometer increase in distance to the nearest forest lead to decrease in fuel wood use by about $36 \mathrm{~kg} / \mathrm{annum}$ per capita, holding the other variable constant.

\section{Determinants of fuel wood collected from public forest}

The results of the three variants of the regression models are presented in Table 4, which explore the determinants of fuel wood collected from public forest, a part of overall fuel wood used in the majority households. The regression results show that out of nine variables selected in the model eight came out to be significant with expected sign in log-lin and Tobit models, and seven in linear model at different levels of significance, reflecting their significant effects on dependent variable. Although the signs bore by estimated coefficients of explanatory variable are found to be almost similar irrespective of the forms of models, the results of Tobit model seems to be more reliable since it has censored the zero values existed in the response variable. Furthermore, since the linear and log-lin models also have revealed presence of some degree of heteroscedasticity one cannot firmly rely on the estimates of these models despite their reasonable value of $\mathrm{R}^{2}$ and significant fit. Moreover, as shown by the estimated Chi square and P-value in Tobit model, the goodness of fit of the model is also reliable.

As in the total fuel wood use, the estimated coefficients of PCINC and PCDANU reveal that these variable have positive and statistically significant influence on per capita fuel wood use collected from public forest. Interestingly, in present case the PCDANU is also came out as statistically significant predictor reflecting the fact that those households who hold higher number of domestic animals also likely to collect more fuel wood per capita form public forest. In contrast to overall fuel wood use, the 
Exploring the Determinants of Fuel wood Use ..... /33

estimated coefficient in PCLH turns out to be negative and statistically significant, implying that level of landholding and dependence on public forest for fuel wood are inversely related. It means a unit change in landholding (i.e. Ropani) would likely to reduce the fuel wood use collected from public forest by about $8 \mathrm{~kg} /$ annum per capita, holding the effect of other variable constant. Caste dummies (i.e. CASTED1 and CASTED2) have also revealed statistically significant positive departure from the base category at 1 and 10 percent level of significance respectively. It means that the households belonging to the two higher caste and ethnic groups are likely to collect significantly higher quantities of fuel wood per capita from public forest than Dalits on the average.

Table 4: Regression results for determinants of per capita fuelwood from public forest

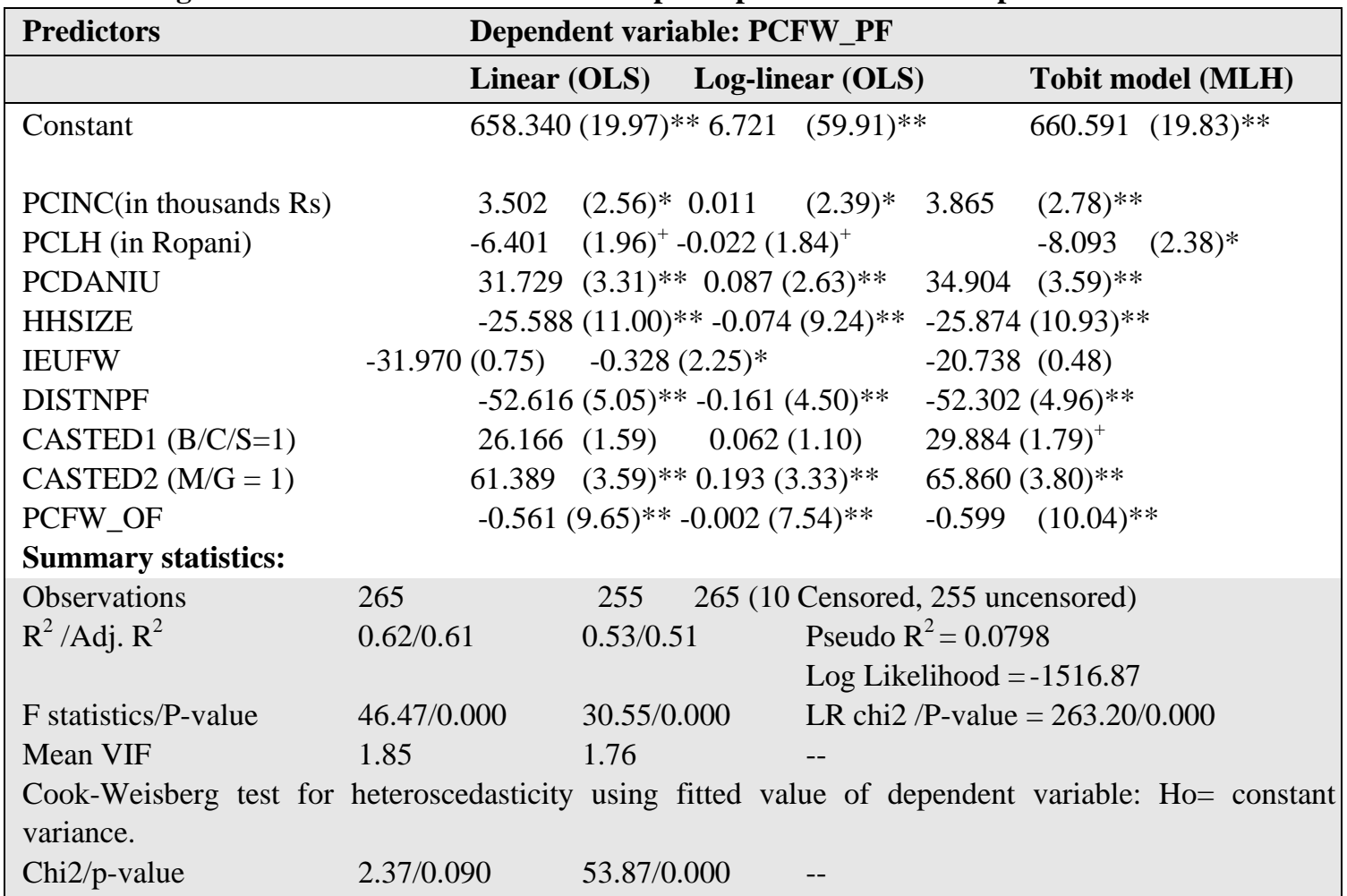

Notes: 1 . Absolute value of $\mathrm{t}$ statistics in parentheses (for tobit estimates $\mathrm{Z}$ statistics)

2. + significant at $10 \%$; significant at $5 \%$; ** significant at $1 \%$,-- not applicable

One new variable introduced in the model, the PCFW_OF, is also come up statistically significant, having expected sign. That is, a unit $(\mathrm{kg})$ increases in per capita fuel wood form private forest/pastures would likely decrease the per capita fuel wood collection from public forest by about $0.5 \mathrm{~kg}$ per annum on the average, holding other variables constant. This inverse relationship also indicates that there exists a clear substitution effect of PCFW_OF on PCFW_PF. Similarly, distance to the nearest forest and the fuel wood collection is found to have negatively and statistically significant impact on response variable. This means the higher the distance the lower the collection of fuel wood from public forest, i.e. a unit $(\mathrm{km})$ increase in distance would likely to reduce the collection per capita by $52.3 \mathrm{~kg} / \mathrm{annum}$ on the average, holding effect of other variable constant. However, as in the overall fuel wood use, in case of per capita fuel wood collected from public forest too, the influence of IEUFW turn out to be insignificant following same reason stated above. 


\section{CONCLUSION AND IMPLICATIONS}

In contrast to the general belief, the households belonging to the higher caste and having higher landholding and higher income are found to use higher quantities of fuel wood per capita, as compared to their counterpart. In case of the fuel wood collected from public forests and the relative dependency on public forests for all the uses the just reverse pattern found to have followed, i.e. the households belonging to lower caste, lower income, lower landholding, larger family size groups are turn of more dependent on public forest. This is due to the status of households in forest and pasture land title, those having no such title have to depend absolutely on public forest for the resources, whereas those having title are naturally enjoy privilege of it.

The findings of multiple regression analysis clearly suggest that the physical quantity of fuelwood used per capita is significantly influenced by the households' socio-economic indicators such as income, household size, landholding, and domestic animal holding per and to some extent caste and ethnicity. That is, income, landholding, and domestic animal holdings per capita have shown positive and significant net effects on fuel wood. But the net effects of household size for the same are appeared negative indicating strong economy of scale of the larger size household on respective per uses. Similarly, the distance to nearest forest is also an important predictor, exhibiting negative and significant effect. But the net effects of per capita landholding on per capita fuel wood collected from public forest appeared to be negative. It is not only an indication of higher dependency of poor on public forests but also an evidence of manifestation of their deprivation.

These results clearly suggest that household economic status defined by per capita income and per capita land holding plays vital role in shaping the pattern of forest resources use at household level. It also imply a fact that the use of forest resource such as fuelwood can be reduced increasing the level of household income per capita or increasing access over productive assets such as land.

\section{REFERENCES}

Adhikari, Bhim (2003). "Property Rights and Natural Resources: Socio-Economic Heterogeneity and Distributional Implications of Common Property Resource Management." Working Paper No. 1-03. Kathmandu: South Asian Network for Development and Environmental Economics (SANDEE).

Amacher, G.S.; W.F. Hyde and K.R. Kanel (1996). "Household Fuel wood Demand and Supply in Nepal's Terai and Mid-Hills: Choice between Cash Outlays and Labour Opportunity." World Development, Vol. 24(11): 1725-1736.

Amacher, G.S.; W.F. Hyde and K.R. Kanel (1999). “ Nepali Feulwood Production and Consumption: Regional and Household Distinction, Substitution and Successful Intervention.” The Journal of Development Studies, Vol.35 (4): 138-163.

Bajracharya, D. (1983). "Fuel, Food or Forest? Dilemmas in a Nepali Village." World Development. 11(2): 1057-74.

Bhattarai, L.N. (2004). Poverty Environment Linkages: A Study of the Use and Management of Forest Resources in Mahabharat Tract, West Nepal. Unpublished Ph. D. Dissertation submitted to Jawarharlal Nehru University, New Delhi.

Gujarati, D.N. (2003). Basic Econometrics (Fourth edition). New York: McGrow-Hill Inc.

Shrestha, R.L. (1986). Socioeconomic Factors Leading to Deforestation in Nepal. Research and Planning Paper Series, No. 2. Kathmandu: HMG-USAID-GTZ-FORD- Winrock Project, Nepal.

Stata Corporation ( 2001). STATA-Version 7.0. Texas USA: Stata Corporation.

Thapa, G.B. and K.E. Weber (1990). Managing Mountain Watershed: The Upper Pokhara Valley, Nepal. Bangkok: Asian Institute of Technology.

UNEP (2001). Nepal: State of Environment-2001. Bangkok: UNEP, Regional Resource Centre for Asia and the Pacific. 